\title{
CT negative subarachnoid hemorrhage in the Emergency Department
}

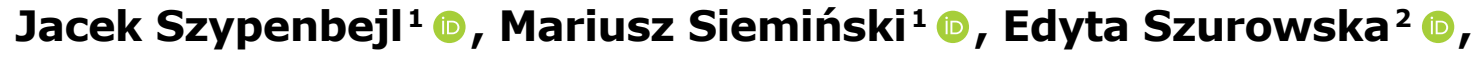

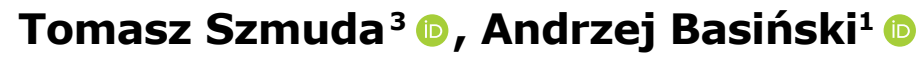

${ }^{1}$ Department of Emergency Medicine, Medical University of Gdańsk, Poland

${ }^{2} 2^{\text {nd }}$ Department of Radiology, Medical University of Gdańsk, Poland

${ }^{3}$ Department of Neurosurgery, Medical University of Gdańsk, Poland

\begin{abstract}
Background: Subarachnoid hemorrhage (SAH) is rare but potentially life-threatening cause of acute headache. First diagnostic test performed in the Emergency Department (ED) for acute "thunderclap" headache is computed tomography of the head (CT) without contrast enhancement. Negative non-contrast head CT may be erroneously interpreted as an exclusion of SAH and lead to ED discharge. The consequences of overlooking SAH are of special interest to the Emergency Physician. The aim of this study was to assess prevalence and clinical picture of CT-negative cases of SAH admitted to the ED. Material and methods: Retrospective analysis of charts of patients admitted to the ED and diagnosed with SAH during 18 consecutive months. Results: Our data gives information about clinical picture of patients with CT-negative SAH and their further clinical course. Out of 126 patients diagnosed with SAH, 5 (4.0\%) were diagnosed with SAH despite negative non-contrast head CT scan. All cases were diagnosed by means of lumbar puncture and analysis of cerebrospinal fluid. In all patients with CT-negative SAH computed tomographic angiography (CTA) was performed and no vascular abnormalities were found. In one case digital subtraction angiography was performed due to equivocal CTA picture and it demonstrated small unruptured aneurysm of the medial cerebral artery. All patients with CT-negative SAH were admitted to a neurological ward and later discharged from the hospital without neurological deficit. There were no episodes of clinical deterioration and none of the patients required an urgent neurosurgical intervention. Conclusions: Although lumbar puncture remains a gold standard in exclusion of SAH, head CT scan without contrast enhancement appears to be a satisfying diagnostic tool in ED.
\end{abstract}

Keywords: emergency department · Computed Tomography · cerebral aneurysm • subarachnoid hemorrhage

\section{Citation}

Szypenbejl J, Siemiński M, Szurowska E, Szmuda T, Basiński A. CT negative subarachnoid hemorrhage in the Emergency Department. Eur J Transl Clin Med. 2020;3(1):43-48.

DOI: $10.31373 /$ ejtcm/122776

\section{Corresponding author:}

Jacek Szypenbejl, Department of Emergency Medicine, Medical University of Gdańsk, Poland

e-mail: jacek.szypenbej|@gmail.com

No external funds.

Available online: www.ejtcm.gumed.edu.pl

Copyright $®$ Medical University of Gdańsk

This is Open Access article distributed under the terms of the Creative Commons Attribution-ShareAlike 4.0 International. 


\section{Introduction}

Headache is the cause of approximately $2 \%$ of Emergency Department (ED) visits [1]. The most important aim of the assessment at an ED is exclusion of a life-threatening disease. One of the potentially devastating conditions in differential diagnosis of severe headache is subarachnoid hemorrhage. Although SAH counts for only $1-3 \%$ headache-related ED visits, ruling out this potentially lethal condition is crucial for the ED physician [1]. Early diagnosis of SAH allows early aggressive treatment and help to prevent re-bleeding episodes which happen in $26-73 \%$ of SAH patients in the days-weeks after the primary bleeding incident [2]. Non-contrast head computed tomography (CT) remains gold standard in diagnosing of SAH [3]. Common diagnostic error is failure to perform a non-contrast head CT scan in patients with clinical suspicion of SAH (headache, nausea and/or vomiting, photophobia, neck stiffness, episodes of loss of consciousness, focal neurological deficits) [2]. Unfortunately, non-contrast head CT scan is not a perfect diagnostic tool because its sensitivity decreases if performed more than 6 hours after symptom onset. Furthermore, there is a group of patients with a normal head CT scan, who still have a strong clinical suspicion of SAH [4]. The next diagnostic procedure in CT-negative cases should be lumbar puncture (LP) with examination of cerebrospinal fluid [5]. Although LP is a frequently performed procedure in the ED, it may result in complications like post-lumbar puncture headache, epidural hematoma, cortical vein thrombosis and reversible cerebral vasoconstriction syndrome [6-7]. Moreover, the decision to continue diagnostic process and perform lumbar puncture significantly prolongs ED length of stay [6].

The primary aim of our study was to assess the prevalence of CT-negative SAH at a single ED. Our secondary aim was to analyze the clinical picture of patients diagnosed with CT-negative SAH and the further course of their disease. Consequences of ED discharge of patients with SAH suspicion and negative non-contrast head CT is of interest to the Emergency Physician community [8].

\section{Material and methods}

We retrospectively analyzed anonymized clinical data of patients admitted to the Emergency Department of the Medical University of Gdańsk and diagnosed with SAH in 18 consecutive months (January 2015-June 2016). We searched for information about the following diagnostic procedures: clinical examination, non-contrast head CT, cerebrospinal fluid analysis (if lumbar puncture was performed), computed tomographic angiography (if performed), cerebral arteriography (if performed). On the basis of this analysis patients diagnosed with SAH with negative non-contrast CT were identified and their clinical data were re-evaluated.

In each patient a non-contrast head CT scan was performed to rule out any potentially life-threatening condition. A radiology specialist assessed each CT scan. If the head CT scan was normal (CT-negative) but the clinical presentation was highly suspicious for spontaneous SAH, a diagnostic lumbar puncture was performed. All conscious patients gave their informed consent prior to undergoing the lumbar puncture procedure. If the patient was presenting with altered mental status and the lumbar puncture was necessary for further, potentially life-saving diagnostic procedures, the clinical context was analyzed and final decision was made by two physicians (neurologist and Emergency Medicine specialist) and documented in the patient's chart. There were 60 such cases in our sample. For better understanding the link between the clinical picture and CT/LP results in CT-negative subjects, we calculated their score according to the Ottawa SAH Rule [7]. There were no additional procedures performed as part of this research project, therefore the local Ethics Committee approval was not necessary.

\section{Results}

Our data shows clinical picture of patients with CT-negative SAH and further course of their disease. We identified the records of 126 patients with subarachnoid hemorrhage admitted to our ED during January 2015-June 2016. SAH was diagnosed by head CT without contrast enhancement in $96.0 \%$ of patients $(n-121)$. There were $5(4.0 \%)$ CT-negative patients who were diagnosed with SAH via CSF analysis. Clinical data of CT-negative and CT-positive patients were presented in Table 1.

Manifestation of CT-negative SAH was not specific. Although all 5 patients complained of headache, in 2 cases vomiting was present. In one case, headache was accompanied by neck stiffness as a manifestation of meningeal syndrome. The average time from first symptoms to head CT was 8 hours with 3 patients exceeding the 6-hour window. Taking into consideration well-known risk factors, one of the patients had history of well-controlled hypertension and chronic alcohol abuse. None of the patients were smokers or received anticoagulant therapy. Family history was not significant. All patients in the CT-negative group were assessed as Grade 1 in the Hunt \& Hess classification while the average grade in the CT-positive group was 2,5. All patients with 
Table 1. Clinical data of the CT-positive and CT-negative patients

\begin{tabular}{|c|c|c|c|}
\hline & $\begin{array}{l}\text { CT-positive } \\
\text { group }\end{array}$ & $\begin{array}{c}\text { CT-negative } \\
\text { group }\end{array}$ & $\mathbf{p}$ \\
\hline Age (years, mean & 55.9 & 50.4 & NS \\
\hline Sex (\% of men) & $43(35.5 \%)$ & $2(40 \%)$ & NS \\
\hline Headache $(n, \%)$ & $98(81 \%)$ & $5(100 \%)$ & NS \\
\hline Vomitting $(n, \%)$ & $53(43.8 \%)$ & $2(40 \%)$ & NS \\
\hline $\begin{array}{c}\text { Meningeal symptoms } \\
(\mathrm{n}, \%)\end{array}$ & $56(46.2 \%)$ & $1(20 \%)$ & NS \\
\hline $\begin{array}{l}\text { Neurological deficit } \\
\qquad(n, \%)\end{array}$ & $78(64.5 \%)$ & $0(0 \%)$ & 0,007 \\
\hline $\begin{array}{l}\text { Cerebral aneurism } \\
\text { found }(n, \%)\end{array}$ & $103(85.1 \%)$ & $1(20 \%)$ & 0.0032 \\
\hline $\begin{array}{c}\text { Neurosurgical } \\
\text { intervention }(n, \%)\end{array}$ & $92(76.0 \%)$ & $0(0) \%$ & 0,0011 \\
\hline Deaths $(n, \%)$ & $34(28.1 \%)$ & $0(0) \%$ & NS \\
\hline
\end{tabular}

Clinical outcome in the CT-negative SAH patients group was favorable. All patients with CT-negative SAH survived and were discharged from the hospital without neurological deficit. None of those patients required any urgent surgical intervention and no episodes of clinical deterioration were observed during their hospital stay.

\section{Discussion}

Our study revealed that $4.0 \%$ of patients diagnosed with SAH at ED had a normal non-contrast head CT. This result is slightly lower than previously published findings showing percentage of CT-negative SAH between 4-20\% [9-11]. The discrepancies may be partially explained with differences in parameters of CT scanner and in experience of radiologists describing the images. Nevertheless, our results demonstrated higher percentages that suggested in the meta-analysis by Dubosh et al, showing that relying solely on non-contrast head CT may lead to missing only

results of cerebrospinal fluid (CSF) analysis typical for SAH underwent CTA with no significant findings. 4 out of 5 CT-negative patients underwent cerebral angiography and an unruptured aneurysm of the middle cerebral artery was found in one subject. The score of CT-negative LP-positive subjects according to the Ottawa SAH Rule was suggesting suspicion of SAH, as shown in Table 2.
$0.15 \%$ of SAH cases. To note, the above results were obtained for patients with "thunderclap" headache and no neurologic deficit, in whom CT was performed within 6 hours of the headache onset [12]. Williams and Sepaul while commenting these results suggested that the Emergency Physican needs to be aware that the CT scan might be negative after the 6-hour window [13].

Table 2. The score of CT-negative LP-positive subjects according to the Ottawa SAH Rule

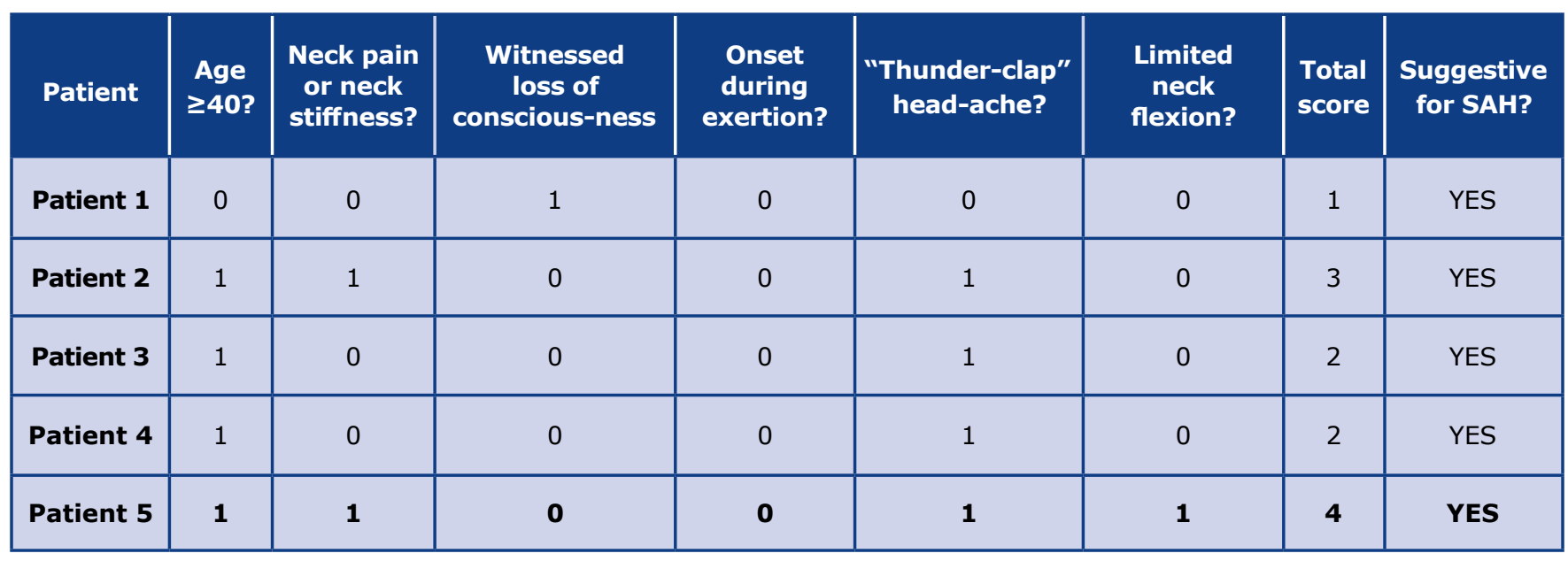


On the contrary, our observations suggest that such practice may lead to overlooking a significant percentage of SAH cases, particularly because all of the CT-negative patients in our sample presented with a "thunderclap" headache and no neurologic deficit.

All 5 of our patients with CT-negative SAH presented with thunderclap headache and only one of them had neck stiffness. This very unspecific clinical presentation is a known feature of SAH. Carpenter et al. confirmed that in their meta-analysis that there are no clinical findings allowing to rule in or to rule out $\mathrm{SAH}$ in patients with acute headache without further diagnostic workup [14]. Our results emphasized that patients with thunderclap headache require thorough diagnostics even with negative head CT. Moreover, it should be noted that there was one case of unruptured aneurysm revealed in patients with negative head $\mathrm{CT}$ that suggests that detailed vascular imaging may lead to significant findings. This finding stays in line with results of Chong et al., who discovered presence of vascular abnormalities in over $40 \%$ of subjects with CT-negative SAH [15].

All patients with CT-negative SAH from our group had a good prognosis - there were no deaths in that group as well as no clinical deterioration (e.g. re-bleeding), or need for urgent neurosurgical intervention. This is in concordance with finding of Mark et al, who analyzed a population of probably overlooked SAH. The authors analyzed clinical course of patients finally diagnosed with $\mathrm{SAH}$ who through 14 days prior the diagnosis were examined due to suspicion of SAH with negative conclusion. They found that probable overlooking of SAH did not influence negatively their prognosis [16]. Chong et al. reported similar observation as only $1.3 \%$ of patients with CT-negative SAH experienced further re-bleeding [15].

Although subarachnoid hemorrhage is a relatively rare cause of headache, failure to recognize it is a familiar clinical scenario for ED physicians [17]. Most of the patients with symptoms suggestive of intracranial hemorrhage are diagnosed in ED, which are known worldwide to be overcrowded [18]. The more laboratory tests, diagnostic images and procedures are performed, the more prolonged length of ED stay and the more patients undergoing assessment and treatment at the same time [19]. Excessive number of patients being treated in ED simultaneously may cause increased hospital mortality [20]. Anecdotally, the most primary purpose of the ED physician is to identify patients in life-threatening condition and to initiate prompt and adequate treatment.

Initial misdiagnosis of SAH may lead to discharge from the ED, followed by a potentially catastrophic re-bleeding episode $[2,21]$. Optimizing the quality of diagnostics and care of patients with suspected SAH is an important issue in recent Emergency Nedicine and Neurology literature. One of the solutions for prolonged diagnostics of headache in ED is extending imaging after originally negative non-contrast head CT scan to include CT-angiography if SAH remains part of the differential diagnosis, which may significantly reduce the risk of overlooking aneurysmal SAH [11]. Another approach is to focus on assessment of initially performed non-contrast head CT scan, as radiological evidence of $\mathrm{SAH}$ is frequently unrecognized [7].

As clinical rules are spreading across the Emergency Medicine community, there is also recently validated Ottawa SAH Rule that can help a physician to rule out subarachnoid hemorrhage in a certain group of patients [22]. Identifying the population with extremely low risk of a life-threatening cause of headache can also help a clinician to use popular worldwide shared decision-making model in which both a patient and medial practitioner understand and accept the risk involved in the decision to finish the diagnostic process [23-24]. Nevertheless, lumbar puncture remains the most sensitive tool to exclude SAH in all cases where the clinical presentation is highly suspicious, clinical rules not applicable and radiology inconclusive for SAH [14, 25].

\section{Conclusions}

Subarachnoid hemorrhage continues to be one of the most important parts of differential diagnosis in population of patients visiting the ED due to headache, head CT scan without contrast enhancement appears to be a satisfactory diagnostic tool to exclude this potentially lethal condition. In our study, only $4.0 \%$ of subarachnoid hemorrhages were diagnosed despite negative non-contrast head CT. The clinical course of CT-negative SAH was mild. It can be presumed that lumbar puncture may be a decisive diagnostic procedure for a minor group of patients with high clinical risk of SAH and inconclusive preceding diagnostic process. This data may increase awareness of incidence of CT-negative SAH and help physicians to properly plan diagnostic procedures after negative head tomography.

\section{Acknowledgements}

This publication was prepared without any external sources of funding. None of the authors has conflict of interests to declare. 


\section{References}

1. Perry JJ, Stiell IG, Sivilotti MLA, Bullard MJ, HohI CM, Sutherland J, et al. Clinical Decision Rules to Rule Out Subarachnoid Hemorrhage for Acute Headache. JAMA [Internet]. 2013;310(12):1248-55. Available from: https://doi.org/10.1001/ jama.2013.278018

2. Kowalski RG. Initial Misdiagnosis and Outcome After Subarachnoid Hemorrhage. JAMA [Internet]. 2004;291(7):866-9. Available from: https://doi.org/10.1001/jama.291.7.866

3. Perry JJ, Stiell IG, Sivilotti MLA, Bullard MJ, Emond M, Symington C, et al. Sensitivity of computed tomography performed within six hours of onset of headache for diagnosis of subarachnoid haemorrhage: prospective cohort study. BMJ [Internet]. 2011;343(jul18 1):d4277-d4277. Available from: https://doi.org/10.1136/bmj.d4277

4. Edlow JA, Panagos PD, Godwin SA, Thomas TL, Decker WW. Clinical Policy: Critical Issues in the Evaluation and Management of Adult Patients Presenting to the Emergency Department With Acute Headache. Ann Emerg Med [Internet]. 2008;52(4):407-36. Available from: https://doi.org/10.1016/i.annemergmed.2008.07.001

5. Gill HS, Marcolini EG, Barber D, Wira CR. The Utility of Lumbar Puncture After a Negative Head CT in the Emergency Department Evaluation of Subarachnoid Hemorrhage. Yale J Biol Med [Internet]. 2018;91(1):3-11. Available from: http:// www.ncbi.nlm.nih.gov/pubmed/29599652

6. Doherty CM, Forbes RB. Diagnostic Lumbar Puncture. Ulster Med J [Internet]. 2014;83(2):93-102. Available from: http:// www.ncbi.nlm.nih.gov/pubmed/4113153

7. Perry JJ, Sivilotti MLA, Sutherland J, Hohl CM, Émond M, Calder LA, et al. Validation of the Ottawa Subarachnoid Hemorrhage Rule in patients with acute headache. Can Med Assoc J [Internet]. 2017;189(45):E1379-85. Available from: https://doi.org/10.1503/cmaj.170072

8. Lansley J, Selai C, Krishnan AS, Lobotesis K, Jäger HR. Subarachnoid haemorrhage guidelines and clinical practice: a cross-sectional study of emergency department consultants' and neurospecialists' views and risk tolerances. BMJ Open [Internet]. 2016;6(9):e012357. Available from: http://dx.doi.org/10.1136/bmjopen-2016-012357

9. Mark DG, Hung Y-Y, Offerman SR, Rauchwerger AS, Reed ME, Chettipally U, et al. Nontraumatic Subarachnoid Hemorrhage in the Setting of Negative Cranial Computed Tomography Results: External Validation of a Clinical and Imaging Prediction Rule. Ann Emerg Med [Internet]. 2013;62(1):1-10.e1. Available from: https://doi.org/10.1016/i.annemergmed.2012.09.003

10. Byyny RL, Mower WR, Shum N, Gabayan GZ, Fang S, Baraff LJ. Sensitivity of Noncontrast Cranial Computed Tomography for the Emergency Department Diagnosis of Subarachnoid Hemorrhage. Ann Emerg Med [Internet]. 2008;51(6):697703. Available from: https://doi.org/10.1016/i.annemergmed.2007.10.007

11. Mark DG, Sonne DC, Jun P, Schwartz DT, Kene M V., Vinson DR, et al. False-negative Interpretations of Cranial Computed Tomography in Aneurysmal Subarachnoid Hemorrhage. O'Neil BJ, editor. Acad Emerg Med [Internet]. 2016;23(5):591-8. Available from: http://doi.wiley.com/10.1111/acem.12941

12. Dubosh NM, Bellolio MF, Rabinstein AA, Edlow JA. Sensitivity of Early Brain Computed Tomography to Exclude Aneurysmal Subarachnoid Hemorrhage. Stroke [Internet]. 2016;47(3):750-5. Available from: https://doi.org/10.1161/STROKEAHA.115.011386

13. Williams TS, Seupaul RA. Can Noncontrast Head Computed Tomography Within 6 Hours of Symptom Onset Exclude Aneurysmal Subarachnoid Hemorrhage? Ann Emerg Med [Internet]. 2016;68(3):352-3. Available from: https://doi. org/10.1016/i.annemergmed.2016.04.034

14. Carpenter CR, Hussain AM, Ward MJ, Zipfel GJ, Fowler S, Pines JM, et al. Spontaneous Subarachnoid Hemorrhage: A Systematic Review and Meta-analysis Describing the Diagnostic Accuracy of History, Physical Examination, Imaging, and Lumbar Puncture With an Exploration of Test Thresholds. Zehtabchi S, editor. Acad Emerg Med [Internet]. 2016;23(9):9631003. Available from: http://doi.wiley.com/10.1111/acem.12984

15. Chong MY, Martin SC, Phang I, St George EJ, Suttner N, Teo MK. The Prevalence of Cerebrovascular Abnormalities Detected in Various Diagnostic Subgroups of Spontaneous Subarachnoid Hemorrhage in the Modern Era. World Neurosurg [Internet]. 2018;111:e355-61. Available from: https://doi.org/10.1016/j.wneu.2017.12.077

16. Mark DG, Kene M V., Vinson DR, Ballard DW. Outcomes Following Possible Undiagnosed Aneurysmal Subarachnoid Hemorrhage: A Contemporary Analysis. Stephen Huff J, editor. Acad Emerg Med [Internet]. 2017;24(12):1451-63. Available from: http://doi.wiley.com/10.1111/acem.13252

17. Yarmohammadian M, Rezaei F, Haghshenas A, Tavakoli N. Overcrowding in emergency departments: A review of strategies to decrease future challenges. J Res Med Sci [Internet]. 2017;22(1):23. Available from: https://doi. org/10.4103/1735-1995.200277 
18. Yoon P, Steiner I, Reinhardt G. Analysis of factors influencing length of stay in the emergency department. CJEM [Internet]. 2003;5(03):155-61. Available from: https://doi.org/10.1017/S1481803500006539

19. Sprivulis PC, Da Silva J-A, Jacobs IG, Frazer ARL, Jelinek GA. The association between hospital overcrowding and mortality among patients admitted via Western Australian emergency departments. Med J Aust [Internet]. 2006;184(5):208-12. Available from: http://www.ncbi.n/m.nih.gov/pubmed/16515429

20. Edlow BL, Samuels O. Emergency Neurological Life Support: Subarachnoid Hemorrhage. Neurocrit Care [Internet]. 2017;27(S1):116-23. Available from: https://doi.org/10.1007/s12028-017-0458-8

21. McCormack RF, Hutson A. Can Computed Tomography Angiography of the Brain Replace Lumbar Puncture in the Evaluation of Acute-onset Headache After a Negative Noncontrast Cranial Computed Tomography Scan? Acad Emerg Med [Internet]. 2010;17(4):444-51. Available from: http://doi.wiley.com/10.1111/j.1553-2712.2010.00694.x

22. Elwyn G, Frosch D, Thomson R, Joseph-Williams N, Lloyd A, Kinnersley P, et al. Shared Decision Making: A Model for Clinical Practice. J Gen Intern Med [Internet]. 2012;27(10):1361-7. Available from: https://doi.org/10.1007/s11606$\underline{012-2077-6}$

23. Long B, Koyfman A. Controversies in the Diagnosis of Subarachnoid Hemorrhage. J Emerg Med [Internet]. 2016;50(6):83947. Available from: https://doi.org/10.1016/i.jemermed.2015.10.020

24. Steffens S, Tucker P, Evans DD. Acute Headache in the Emergency Department. Adv Emerg Nurs J [Internet]. 2018;40(2):7886. Available from: http://journals.Iww.com/01261775-201804000-00002

25. Grasso G, Alafaci C, Macdonald RI. Management of aneurysmal subarachnoid hemorrhage: State of the art and future perspectives. Surg Neurol Int [Internet]. 2017;8(1):11. Available from: https://doi.org/10.4103/2152-7806.198738 